\title{
Effect of oral prednisolone on response to salbutamol and ipratropium bromide aerosols in patients with chronic airflow obstruction
}

\author{
PGD CURZON, MA MARTIN, NJ COOKE, MF MUERS \\ From the Department of Chest Medicine, Killingbeck Hospital, Leeds
}

\begin{abstract}
We examined the bronchodilator responses to inhalation of salbutamol (200 $\mu \mathrm{g})$ and of ipratropium bromide $(40 \mu \mathrm{g})$ in the morning and in the afternoon before and during a course of oral prednisolone ( $40 \mathrm{mg}$ daily) in 15 patients with chronic, partly reversible airflow obstruction. Bronchodilatation was assessed by measuring serial peak expiratory flow rates (PEFR) for six hours after aerusol drug administration and calculating the area under the time-response curves. Eleven patients were found to be corticosteroid resistant in not attaining a baseline bronchodilatation of at least $25 \%$ during corticosteroid treatment. These patients also failed to show any enhancement of their bronchodilator responses to either salbutamol or ipratropium bromide during prednisolone administration. We therefore conclude that there is no rationale for giving or continuing corticosteroid treatment in known steroid-resistant patients in the hope of nevertheless potentiating their bronchodilator responses to salbutamol or ipratropium bromide.
\end{abstract}

Corticosteroids have been used to treat airflow obstruction in acute and chronic asthma for over 30 years. ${ }^{1-3}$ Their use in chronic bronchitis is more controversial but a trial of corticosteroid treatment is often indicated. ${ }^{4-8}$ Evidence has been accumulating for various cellular effects of corticosteroids that may result in bronchial relaxation and it has been suggested that one possible mode of action may be by the potentiation of endogenous and exogenous catecholamines. ${ }^{9-11}$

There is a subgroup of patients with partly reversible airflow obstruction in response to bronchodilator drugs who do not show bronchodilatation with corticosteroid treatment. Our study was designed to determine whether corticosteroid treatment might nevertheless be of benefit in these patients by enhancing the bronchodilatation normally achieved with either salbutamol, a $\beta$-adrenergic agonist related to the catecholamines, or ipratropium bromide, a parasympatholytic agent, given by pressurised aerosols in conventional doses. These two bronchodilators with different actions

Address for reprint requests: Dr MF Muers, Killingbeck Hospital, York Road, Leeds LS14 6UQ.

Accepted 28 March 1983 were compared to determine any possible specificity of potentiation of either by prednisolone.

\section{Patients and methods}

Fifteen patients (mean age 64 years) with chronic airflow obstruction were studied. All had been having long-term bronchodilator treatment but persistent symptoms were severe enough to warrant a trial of oral corticosteroid treatment. None had received oral corticosteroids during the previous month, although one patient was taking inhaled beclomethasone dipropionate, which was continued throughout. Selection criteria were: (a) evidence of airflow obstruction obtained by measuring the forced expiration in the first second $\left(\mathrm{FEV}_{1}\right)$ and the forced vital capacity (FVC) with a Collins spirometer, the $\mathrm{FEV}_{1} / \mathrm{FVC}$ being under $75 \%$ and the FEV under $80 \%$ of the predicted value ${ }^{12}$; and $(b)$ sufficient reversibility to produce at least a $15 \%$ incremental response in the $\mathrm{FEV}_{1}$ with each of separate inhaled doses of salbutamol $200 \mu \mathrm{g}$ and of ipratropium bromide $40 \mu \mathrm{g}$ given by standard metered-dose:aerosols (two puffs of each). Patients with acute bronchospasm or overt cardiovascular disease were excluded. All who entered the study 
Table 1 Design of the study

\begin{tabular}{|c|c|c|c|c|c|c|c|c|c|c|c|c|c|}
\hline Day & & 1 & 2 & 3 & 4 & 5 & 6 & 7 & 8 & 9 & 10 & 11 & 12 \\
\hline $\begin{array}{c}\text { Aerosol } \\
\text { drug }\end{array}$ & $\begin{array}{r}10 \mathrm{am} \\
4 \mathrm{pm}\end{array}$ & $\begin{array}{l}\mathbf{P} \\
\mathbf{P}\end{array}$ & $\begin{array}{l}\mathbf{A} \\
\mathbf{B}\end{array}$ & $\begin{array}{l}\text { B } \\
\text { A }\end{array}$ & $\begin{array}{l}\mathbf{A} \\
\mathbf{B}\end{array}$ & $\begin{array}{l}\text { B } \\
\text { A }\end{array}$ & $\begin{array}{l}\mathbf{A} \\
\mathbf{B}\end{array}$ & $\begin{array}{l}\text { B } \\
\text { A }\end{array}$ & $\begin{array}{l}\mathbf{A} \\
\mathbf{B}\end{array}$ & $\begin{array}{l}\text { B } \\
\mathbf{A}\end{array}$ & $\begin{array}{l}\mathbf{A} \\
\mathbf{B}\end{array}$ & $\begin{array}{l}\mathbf{B} \\
\mathbf{P}\end{array}$ & $\mathbf{P}$ \\
\hline
\end{tabular}

$P$ represents the pair of aerosol inhalers placebo 1 and placebo 2 ; $A$ the pair of aerosol inhalers active 1 and placebo 2 ; and $B$ the reverse pair, placebo 1 and active 2 . For each patient the allocation of either salbutamol or ipratropium bromide to the active 1 inhaler was random and double blind; hence the active 2 inhaler was the other of these two drugs. Placebo and prednisolone tablets were given in a single-blind manner.

gave their informed consent and were admitted to hospital. Their routine medication, other than $\beta$-agonist or anticholinergic bronchodilators, was continued throughout. Three patients continued treatment with oral aminophylline.

On each of 12 successive inpatient days responses to placebo, salbutamol, or ipratropium bromide inhalers were assessed during a morning (10 am) and an afternoon (4 pm) study session by measurement of the peak expiratory flow rate (PEFR) with a Wright peak flow meter. The result for the best of three attempts was recorded. Measurements were made at one, five, 15 , and 30 minutes and one, two, three, four, five, and six hours afterwards. The study design is shown diagrammatically in table 1 ; from day 2 to day 11 morning active inhalers, either salbutamol $200 \mu \mathrm{g}$ or ipratropium bromide $40 \mu \mathrm{g}$ (two puffs per inhaler) were given. Each drug was assessed once daily and the time of assessment (that is, morning or afternoon) alternated daily but the allocation of the drugs was randomised as indicated in table 1 and they were given in a double-blind manner. Patients received placebo tablets twice daily on days one, two, three, 11 , and 12 and prednisolone tablets $20 \mathrm{mg}$ twice daily on days $4-10$ on a single-blind basis.

Corticosteroid responsiveness was evaluated by calculating the average percentage change in the prebronchodilator baseline PEFR on day 10 (the seventh day of prednisolone administration) from the mean prebronchodilator baseline PEFR of days 1-3 (before prednisolone administration) for the morning and afternoon study sessions. Those patients who did not reach a $25 \%$ increment were defined as steroid resistant.

Bronchodilator responses were calculated from PEFR measurements by two methods: (a) trapezoidal integration of the area under the time-response curves over six hours, which provides a measure of both the magnitude and the persistence of the response without relating it to any change in baseline value, and (b) the percentage incremental response one hour after the inhaler, which does relate the effect to the baseline value. Placebo effects were subtracted and values analysed by Student's paired $t$ test for morning versus afternoon

Table 2 Data on 11 steroid-resistant patients

\begin{tabular}{|c|c|c|c|c|c|c|c|c|}
\hline Patient & $\begin{array}{l}\text { Age } \\
(y)\end{array}$ & Sex & $\begin{array}{l}\text { Initial FEV } \\
\text { (\% pred) }\end{array}$ & $\begin{array}{l}\text { Initial } \\
\text { FEV /FVC } \\
(\%)\end{array}$ & $\begin{array}{l}\text { Final FEV } \\
(\% \text { pred })\end{array}$ & $\begin{array}{l}\text { Final } \\
\text { FEV } / F V C \\
(\%)\end{array}$ & $\begin{array}{l}\text { Final ba } \\
\text { \% chan } \\
\text { am }\end{array}$ & PEFR \\
\hline $\begin{array}{r}1 \\
2 \\
3 \\
4 \\
5 \\
6 \\
7 \\
8 \\
9 \\
10 \\
11\end{array}$ & $\begin{array}{l}63 \\
62 \\
78 \\
54 \\
74 \\
66 \\
63 \\
57 \\
61 \\
66 \\
63\end{array}$ & $\begin{array}{l}\mathbf{F} \\
\mathbf{F} \\
\mathbf{M} \\
\mathbf{M} \\
\mathbf{M} \\
\mathbf{M} \\
\mathbf{M} \\
\mathbf{M} \\
\mathbf{M} \\
\mathbf{M} \\
\mathbf{M}\end{array}$ & $\begin{array}{l}47 \\
66 \\
26 \\
78 \\
22 \\
38 \\
44 \\
32 \\
23 \\
70 \\
75\end{array}$ & $\begin{array}{l}50 \\
68 \\
24 \\
67 \\
29 \\
40 \\
44 \\
37 \\
48 \\
49 \\
70\end{array}$ & $\begin{array}{l}56 \\
57 \\
26 \\
92 \\
42 \\
37 \\
51 \\
32 \\
32 \\
75 \\
75\end{array}$ & $\begin{array}{l}47 \\
53 \\
21 \\
61 \\
35 \\
42 \\
41 \\
39 \\
50 \\
50 \\
68\end{array}$ & $\begin{array}{r}-3 \\
+16 \\
-5 \\
-1 \\
+9 \\
+9 \\
+2 \\
0 \\
+7 \\
-7 \\
+17\end{array}$ & $\begin{array}{r}-4 \\
+16 \\
+4 \\
0 \\
+30 \\
+17 \\
+2 \\
-3 \\
+8 \\
+3 \\
+25\end{array}$ \\
\hline $\begin{array}{l}\text { Mean } \\
\pm \text { SEM }\end{array}$ & $64 \pm 2$ & & $47.4 \pm 6.5$ & $47.8 \pm 4.7$ & $52.3 \pm 6.4$ & $46.1 \pm 3.8$ & $4 \pm 2.5$ & $8.9 \pm 3.5$ \\
\hline
\end{tabular}

$\%$ pred-percentage of predicted normal value ${ }^{12} ; \mathrm{FEV}_{1}$ - forced expiratory volume in one second; FVC - forced vital capacity; PEFRpeak expiratory flow rate. 
baseline values and by the unpaired $t$ test for group comparison of responses to aerosol inhalers. Differences were regarded as significant at the $5 \%$ level.

\section{Results}

All 15 patients completed the study. Four patients were found to respond to prednisolone and their results were therefore excluded from the main analysis. Data for the 11 steroid-resistant patients are shown in table 2 .

The two methods of calculating the PEFR responses gave similar results (fig). Afternoon responses were consistently smaller than morning ones and were associated with higher afternoon baseline values. This difference between morning and afternoon baseline values was not significant on day $1(p=0.25)$ but did reach significance on day 2 $(\mathrm{p}<0.02)$ and day $3(\mathrm{p}=0.05)$. There was no significant difference between the bronchodilatation achieved by salbutamol before and during prednisolone administration. Similarly, there was no significant difference between the bronchodilatations achieved by ipratropium bromide before and during prednisolone administration. Moreover, there was no significant difference between the bronchodilatation achieved by salbutamol and by ipratropium bromide either before prednisolone administration or during it. For no individual was there any significant difference between morning and evening PEFR values measured one hour after inhalation of a bronchodilator.

Some data were available on the four steroidresponsive patients. Analysis indicated that these patients did not show significantly enhanced bronchodilator responses during prednisolone adminis- tration. Because of the small number of these patients, however, a valid conclusion could not be drawn.

\section{Discussion}

The difficulty in predicting corticosteroid responsiveness or unresponsiveness in patients with chronic airflow obstruction is well known. ${ }^{81314}$ For the purpose of this study therefore patients were selected on the grounds of having some reversibility of their airflow obstruction and responding to both the bronchodilator agents used. ${ }^{15}$

The PEFR, although to some extent effort dependent, has been found to be as sensitive as other tests of airways obstruction in assessing bronchodilator drugs $^{16}$ and is an accepted measurement for this purpose. ${ }^{17}$

It is known that during a trial of corticosteroid treatment in chronic airflow obstruction some improvement may be noted after three hours ${ }^{16}$ but the maximum response may not be reached for six days ${ }^{10}$ or eight days. ${ }^{18}$ In the present study a sevenday course of prednisolone was chosen.

Shenfield et al noted an enhanced response to inhaled isoprenaline during prednisone administration in six of nine asthmatic patients, and interpreted this effect as potentiation of isoprenaline by corticosteroids. ${ }^{10}$ Lightbody et al noted a marginal incremental response when adding oral prednisolone for three days to combined treatment with salbutamol and ipratropium bromide by aerosol, again in asthmatics. ${ }^{19}$ Interpreting these effects is complicated because in some patients the degree of bronchodilatation achieved by bronchodilators may depend on the variable baseline bronchial relaxa-

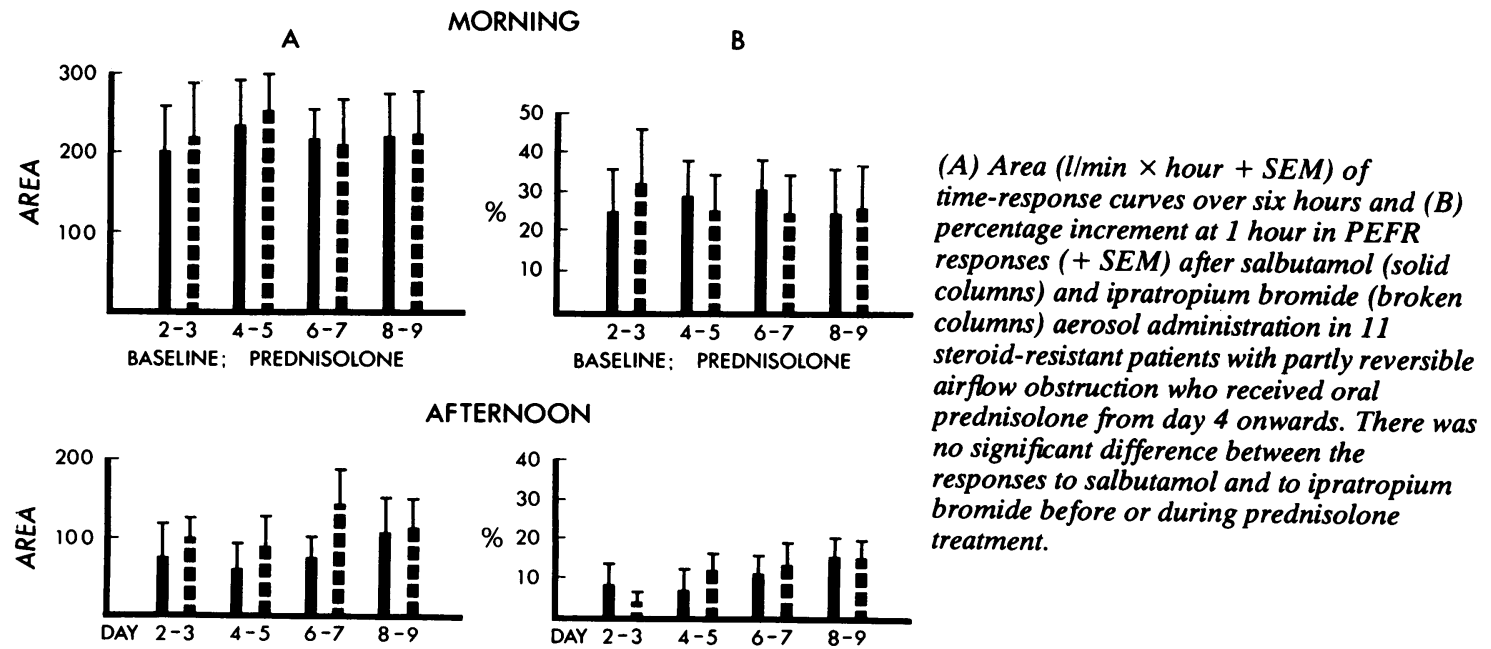


tion, as shown by Hume and Rhys Jones, ${ }^{20}$ while in others it may be much less regular. ${ }^{21}$ No such additional bronchodilatation attributable to corticosteroids was found in chronic bronchitic patients. ${ }^{10141922}$

In our study we did not categorise patients according to a specific diagnosis, but all had a degree of reversibility in airflow obstruction to bronchodilators and may therefore be considered to have had an asthmatic component. Our results enlarge on the findings of the above-mentioned studies and show that in the absence of a baseline response to prednisolone in conventional dosage no enhancement of bronchodilator response to either salbutamol or ipratropium bromide given in the usual dose by pressurised aerosol inhaler may be expected. We have found a consistent diurnal variation with lower afternoon responses attributable to higher baseline values. This variation was not affected by prednisolone. Diurnal variation is known to occur in normal people, chronic bronchitics, ${ }^{23}$ and, with greater amplitude, asthmatics. ${ }^{24}$ In our patients part of the effect seems to have been due to a carry-over from the morning bronchodilator as it was significantly different on activeinhaler as opposed to placebo-inhaler days. As the postbronchodilator PEFR values in any one patient were similar for mornings and afternoons, probably the difference in the bronchodilator responses obtained was due to the difference in the baseline values.

We are grateful to Dr RL Page for allowing us to include some of his patients, to Mrs S Baker and Mrs $R$ Bunting for technical assistance, and to Boehringer Ingelheim for supplying ipratropium bromide in the form of Atrovent as well as placebo inhalers.

\section{References}

${ }^{1}$ Carryer HM, Koelsche GA, Prickman LE, Maytum CK, Lake CF, Williams HL. Effects of cortisone on bronchial asthma and hay fever occurring in subjects sensitive to ragweed pollen. Mayo Clin Proc 1950; 25:482-6.

${ }^{2}$ Medical Research Council. Controlled trial of effects of cortisone acetate in status asthmaticus. Lancet 1956;ii:803-6.

${ }^{3}$ Phear D, Ball K, Page F. Prolonged treatment with steroids in severe chronic asthma. Lancet 1960;i:139-41.

${ }^{4}$ Clifton M, Stuart-Harris CH. Steroid therapy in chronic bronchitis. Lancet 1962;i:1311-3.
5 Freedman BJ. Bronchodilators and corticosteroids in chronic bronchitis and emphysema. $\mathrm{Br} \mathrm{Med} J$ 1963;ii:1509-12.

- Beerel F, Vance JW. Prednisone treatment for stable pulmonary emphysema. Am Rev Respir Dis 1971;104:264-6.

${ }^{7}$ Evans JA, Morrison IM, Saunders KB. A controlled trial of prednisone, in low dosage, in patients with chronic airways obstruction. Thorax 1974;29:401-6.

${ }^{8}$ Sahn SA. Corticosteroids in chronic bronchitis and pulmonary emphysema. Chest 1978;73:389-96.

${ }^{9}$ Kalsner S. Mechanisms of hydrocortisone potentiation of responses to epinephrine and norepinephrine in rabbit aorta. Circ Res 1969;24:383-95.

${ }^{10}$ Shenfield GM, Hodson ME, Clarke SW, Paterson JW. Interaction of corticosteroids and catecholamines in the treatment of asthma. Thorax 1975;30:430-5.

"Ellul-Micallef R, Fenech FF. Effect of intravenous prednisolone in asthmatics with diminished adrenergic responsiveness. Lancet $1975 ; \mathrm{ii}: 1269-70$.

12 Committee on Rating of Mental and Physical Impairment. The respiratory system. JAMA 1965; 194:919-32.

${ }^{13}$ Beerel F, Jick H, Tyler JM. A controlled study of the effect of prednisone on air-flow obstruction in severe pulmonary emphysema. $N$ Engl J Med 1963; 268:226-30.

${ }^{14}$ Harding SM, Freedman S. A comparison of oral and inhaled steroids in patients with chronic airways obstruction: features determining response. Thorax 1978;33:214-8.

${ }^{15}$ Clark TJH. Definition of asthma for clinical trials. In: Stark JE, Collins JV, ed. Methods in clinical trials in asthma. Br J Dis Chest 1977;71:225-7.

${ }^{16}$ Ellul-Micallef R, Borthwick RC, McHardy GJR. The time-course of response to prednisolone in chronic bronchial asthma. Clin Sci Molec Med 1974;47:10517.

${ }^{17}$ Pride NB. Which physiological tests? In: Stark JE, Collins JV, ed. Methods in clinical trials in asthma. $\mathrm{Br} J$ Dis Chest 1977;71:230-2.

${ }^{18}$ Webb J, Clark TJH, Chilvers C. Time course of response to prednisolone in chronic airflow obstruction. Thorax 1981;36:18-21.

${ }^{19}$ Lightbody IM, Ingram CG, Legge JS, Johnston RN. Ipratropium bromide, salbutamol and prednisolone in bronchial asthma and chronic bronchitis. $\mathrm{Br} J \mathrm{Dis}$ Chest 1978;72:181-6.

${ }^{20}$ Hume KM, Rhys Jones $\mathrm{E}$. The response to bronchodilators in intrinsic asthma. $Q J \operatorname{Med}(N S)$ 1961;30:189-99.

${ }^{21}$ Freedman BJ. Patterns of response to bronchodilators in asthma. Br J Dis Chest 1978;72:95-107.

22 Shim C, Stover DE, Williams MH. Response to corticosteroids in chronic bronchitis. J Allergy Clin Immunol 1978;62:363-7.

${ }^{23}$ Dawkins KD, Muers MF. Diurnal variation in airflow obstruction in chronic bronchitis. Thorax 1981;36:618-21.

${ }^{24}$ Clark TJH, Hetzel MR. Diurnal variation of asthma. $\mathrm{Br}$ J Dis Chest 1977;71:87-92. 